\title{
Increasing trends in hospital care burden of atrial fibrillation in Korea, 2006 through 2015
}

\author{
Daehoon Kim, ${ }^{1}$ Pil-Sung Yang, ${ }^{1,2}$ Eunsun Jang, ${ }^{1}$ Hee Tae Yu, ${ }^{1}$ Tae-Hoon Kim, ${ }^{1}$ \\ Jae-Sun Uhm, ${ }^{1}$ Jong Youn Kim, ${ }^{1}$ Hui-Nam Pak, ${ }^{1}$ Moon-Hyoung Lee, ${ }^{1}$ Boyoung Joung, \\ Gregory Y H Lip ${ }^{3,4}$
}

- Additional material is

published online only. To view, please visit the journal online (http://dx.doi.org/10.1136/ heartjnl-2017-312930).

'Division of Cardiology, Department of Internal Medicine, Yonsei University Health System, Seoul, Republic of Korea

2Department of Cardiology, CHA Bundang Medical Center, CHA University, Seongnam, Republic of Korea

${ }^{3}$ Institute of Cardiovascular Sciences, University of Birmingham, Birmingham, UK ${ }^{4}$ Department of Clinical Medicine, Aalborg Thrombosis Research Unit, Aalborg University, Aalborg, Denmark

\section{Correspondence to}

Proffessor Boyoung Joung, Division of Cardiology, Department of Internal Medicine, Yonsei University Health System, Seoul 03722, Republic of Korea; cby6908@ yuhs.ac and Proffessor Gregory Y H Lip, Institute of Cardiovascular Sciences, University of Birmingham, Birmingham, Englandv B15 2TT, UK; g.y.h.lip@bham.ac.uk

DK and P-SY contributed equally.

BJ and GYHL are joint senior authors.

Received 29 December 2017

Revised 27 March 2018

Accepted 30 March 2018

Published Online First

17 April 2018

\section{Linked}

- http://dx.doi.org/10.1136/ heartjnl-2018-313350

Check for updates

To cite: Kim D, Yang P-S, Jang $E_{\text {, et al. Heart }}$ 2018:104:2010-2017

\section{ABSTRACT \\ Objective Temporal changes in the healthcare} burden of atrial fibrillation (AF) are less well known in rapidly ageing Asian countries. We examined trends in hospitalisations, costs, treatment patterns and outcomes related to AF in Korea.

Methods Using the National Health Insurance Service (NHIS) database involving the entire adult Korean population ( $n=41701269$ in 2015), we analysed a nationwide AF cohort representing 931138 patients with AF. We studied all hospitalisations due to AF from 2006 to 2015 .

Results Overall, hospitalisations for AF increased by $420 \%$ from 767 to 3986 per 1 million Korean population from 2006 to 2015. Most admissions occurred in patients aged $\geq 70$ years, and the most frequent coexisting conditions were hypertension, heart failure and chronic obstructive pulmonary disease. Hospitalisations mainly due to major bleeding and AF control increased, whereas hospitalisations mainly due to ischaemic stroke and myocardial infarction decreased. The total cost of care increased even after adjustment for inflation from €68.4 million in 2006 to €388.4 million in 2015 , equivalent to $0.78 \%$ of the Korean NHIS total expenditure. Overall in-hospital mortality decreased from $7.5 \%$ in 2006 to $4.3 \%$ in 2015 . The in-hospital mortality was highest in patients $\geq 80$ years of age $(7.7 \%)$ and in patients with chronic kidney disease (7.4\%).

Conclusions AF hospitalisations have increased exponentially over the past 10 years in Korea, in association with an increase in comorbid chronic diseases. Mortality associated with AF hospitalisations decreased during the last decade, but hospitalisation costs have markedly increased.

\section{INTRODUCTION}

Atrial fibrillation (AF) is the most common sustained cardiac arrhythmia in the general population, and is associated with increased mortality and morbidity. ${ }^{1}$ The number of persons with AF has been projected to increase to $12.1-15.9$ million in the USA by 2050 and 17.9 million in Europe by 2060, with more than half of these patients $\geq 80$ years of age. $^{2-4}$ Consequently, the healthcare burden of AF is growing considerably, and is mainly related to hospitalisations. ${ }^{5-7}$ The total cost related to AF care was estimated as US\$6-US\$2 6 billion in the USA and it accounts for $1 \%$ of the national healthcare budget in the UK. ${ }^{5-7}$
While the global burden of AF has increased over recent decades, most studies about the epidemiology and care burden of AF are based on the predominantly white populations of North America or Europe. ${ }^{8}$ The actual disease burden of AF in Asia is rapidly increasing given the larger proportional increase in the elderly population. ${ }^{9}{ }^{10}$ However, the impact of AF on hospitalisations and mortality, and the economic burden of AF is less understood in Asian populations. A nation-level study of the temporal trends in healthcare burden of AF is essential for establishing the burden of AF and appropriate healthcare planning. Therefore, we used a national insurance database to evaluate a contemporary AF-related hospital care burden. We examined temporal trends in hospitalisations, the effects of comorbid diagnoses, costs, treatment patterns and outcomes related to AF in Korea.

\section{METHODS}

\section{Data sources}

This study is based on the national health claims database established by the National Health Insurance Service (NHIS) of Korea. ${ }^{11}$ The NHIS is the single insurer managed by the Korean government, and the majority (97.1\%) of the Korean population are mandatory subscribers, while the remaining $3 \%$ of the population are medical aid subjects. The NHIS database contains information on medical aid subjects as well; therefore, it is based on the entire Korean population. The following medical information is provided: sociodemographic information, patient use of inpatient and outpatient services, pharmacy dispensing claims and mortality data. Every population in the NHIS database was linked by Korean social security numbers, and all social security numbers were deleted after constructing the cohort by using serial numbers to prevent leakage of personal information. These databases are open to researchers, whose study protocols are approved by the official review committee. Informed consent was waived.

\section{Study population}

Between 1 January 2006 and 31 December 2015, 931138 patients with AF were identified from the entire Korean population. AF was diagnosed using the International Classification of Disease 10th Revision (ICD-10) codes I48 (AF and atrial flutter), I48.0 (AF) and I48.1 (atrial flutter). To ensure diagnostic accuracy, patients were defined as having 
AF only when it was a discharge diagnosis or confirmed more than twice in the outpatient department. ${ }^{12-17}$ Diagnosis of AF has previously been validated in the NHIS database with a positive predictive value of $94.1 \% .^{15}{ }^{17}$ Patients aged $<20$ years or with valvular AF (with a diagnosis of either mitral stenosis (ICD10: I05.0, I05.2 and I34.2) or prosthetic heart valves (ICD-10: Z95.2-Z95.4) or insurance claims for valve replacement or valvuloplasty) were excluded.

All hospitalisations due to AF from 2006 to 2015 and the cost of each inpatient stay were studied. AF hospitalisations and inpatient costs were obtained in two different ways: 1) overall $\mathrm{AF}$ hospitalisation (AF as any diagnosis of up to five discharge diagnoses) and 2) AF hospitalisation due to each main cause including major bleeding, ischaemic stroke, AF control (AF as principal discharge diagnosis), myocardial infarction (MI), heart failure, sick sinus syndrome (SSS) or pacemaker (PM) related, and radiofrequency catheter ablation (RFCA) for AF. All costs were calculated in Korean won (KRW) and converted into Euros
(1 EUR $=1282.7 \mathrm{KRW})$. Cost was adjusted for inflation by calculating in terms of the 2015 cost using the Korean Consumer Price Index data. ${ }^{18}$

\section{Comorbidities, economic status and medications}

Comorbidities were defined using medical claims according to ICD-10 codes and prescription medication use. To ensure diagnostic accuracy, patients were considered to have comorbidities when it was a discharge diagnosis or was confirmed more than twice in an outpatient setting, similar to previous studies with the NHIS. ${ }^{12} 13$ 15-17 The definitions of comorbidities and main hospitalisation causes are presented in online supplementary table 1. Economic status variables were categorised into three groups based on the total amount of national health insurance premiums paid by an insured person in each year, which is proportional to the person's income: low, intermediate and high economic status. Prescription medication use was ascertained

Table 1 Characteristics of patients with AF hospitalisations

\begin{tabular}{|c|c|c|c|c|c|c|c|c|c|c|c|}
\hline & 2006 & 2007 & 2008 & 2009 & 2010 & 2011 & 2012 & 2013 & 2014 & 2015 & $\begin{array}{l}P \text { value for } \\
\text { trend }\end{array}$ \\
\hline Total Korean AF population, $\mathrm{n}$ & 269448 & 315854 & 359695 & 402024 & 442657 & 481682 & 520070 & 558651 & 598614 & 639349 & \\
\hline $\begin{array}{l}\text { Patients with hospitalisations, } \\
\mathrm{n}(\%)\end{array}$ & $\begin{array}{l}16639 \\
(6.2)\end{array}$ & $\begin{array}{l}20539 \\
(6.5)\end{array}$ & $\begin{array}{l}24948 \\
(6.9)\end{array}$ & $\begin{array}{l}28345 \\
(8.2)\end{array}$ & $\begin{array}{l}33214 \\
(7.1)\end{array}$ & $\begin{array}{l}36025 \\
(7.5)\end{array}$ & $\begin{array}{l}41421 \\
(8.0)\end{array}$ & $\begin{array}{l}46012 \\
(8.2)\end{array}$ & $\begin{array}{l}51223 \\
(8.6)\end{array}$ & $\begin{array}{l}58160 \\
(9.1)\end{array}$ & $<0.001$ \\
\hline \multicolumn{12}{|l|}{ Sex, \% } \\
\hline Male & 55.4 & 54.8 & 53.9 & 54.6 & 54.3 & 54.3 & 54.1 & 54.0 & 53.9 & 53.6 & $<0.001$ \\
\hline Female & 44.6 & 45.2 & 46.1 & 45.4 & 45.7 & 45.7 & 45.9 & 46.0 & 46.1 & 46.4 & $<0.001$ \\
\hline Age, mean (SE) & $\begin{array}{l}69.5 \\
(0.9)\end{array}$ & $\begin{array}{l}70.0 \\
(0.8)\end{array}$ & $\begin{array}{l}70.6 \\
(0.7)\end{array}$ & $\begin{array}{l}70.9 \\
(0.7)\end{array}$ & $\begin{array}{l}71.1 \\
(0.6)\end{array}$ & $\begin{array}{l}71.4 \\
(0.6)\end{array}$ & $\begin{array}{l}71.9 \\
(0.5)\end{array}$ & $\begin{array}{l}72.3 \\
(0.3)\end{array}$ & $\begin{array}{l}72.9 \\
(0.5)\end{array}$ & $\begin{array}{l}73.3 \\
(0.5)\end{array}$ & $<0.001$ \\
\hline 20-49years, \% & 6.0 & 5.8 & 5.2 & 5.1 & 4.8 & 4.4 & 4.2 & 3.6 & 3.6 & 3.4 & $<0.001$ \\
\hline 50-59years, \% & 10.9 & 10.5 & 9.8 & 9.9 & 10.0 & 10.1 & 10.2 & 10.0 & 9.4 & 8.9 & $<0.001$ \\
\hline $60-69$ years, \% & 27.7 & 26.2 & 24.7 & 23.9 & 22.9 & 22.2 & 20.9 & 19.5 & 18.5 & 18.3 & $<0.001$ \\
\hline 70-79years, \% & 37.5 & 38.4 & 39.2 & 39.0 & 39.3 & 38.9 & 38.8 & 39.5 & 38.9 & 37.6 & $<0.001$ \\
\hline$\geq 80$ years, $\%$ & 18.0 & 19.1 & 21.0 & 22.2 & 23.0 & 24.4 & 25.9 & 27.4 & 29.7 & 31.9 & $<0.001$ \\
\hline \multicolumn{12}{|l|}{ Economic status, \% } \\
\hline Low & 45.1 & 46.3 & 45.3 & 44.1 & 42.9 & 42.5 & 41.2 & 39.9 & 38.1 & 36.5 & $<0.001$ \\
\hline Intermediate & 20.9 & 20.6 & 25.0 & 24.3 & 24.1 & 24.0 & 24.1 & 24.2 & 24.2 & 24.4 & $<0.001$ \\
\hline High & 34.0 & 33.2 & 29.7 & 31.6 & 32.9 & 33.5 & 34.7 & 35.9 & 37.7 & 39.1 & $<0.001$ \\
\hline \multicolumn{12}{|c|}{ Practice level of initial AF diagnosis } \\
\hline Primary care hospital & 3.7 & 4.5 & 5.4 & 6.0 & 6.6 & 7.5 & 8.3 & 8.7 & 9.0 & 9.2 & $<0.001$ \\
\hline Secondary care hospital & 9.7 & 9.9 & 10.7 & 12.3 & 12.6 & 11.2 & 9.8 & 9.4 & 9.7 & 9.5 & $<0.001$ \\
\hline Tertiary referral hospital & 85.3 & 83.4 & 82.4 & 80.0 & 79.2 & 79.5 & 79.9 & 79.7 & 79.0 & 78.8 & $<0.001$ \\
\hline $\begin{array}{l}\text { Others (nursing/public } \\
\text { health centre) }\end{array}$ & 1.3 & 2.2 & 1.6 & 1.6 & 1.6 & 1.7 & 2.0 & 2.2 & 2.3 & 2.4 & $<0.001$ \\
\hline \multicolumn{12}{|l|}{ Comorbidities, \% } \\
\hline Heart failure & 69.6 & 70.2 & 69.5 & 69.8 & 69.6 & 70.4 & 70.8 & 71.4 & 72.8 & 73.8 & $<0.001$ \\
\hline Hypertension & 95.3 & 95.8 & 96.0 & 96.4 & 96.3 & 96.1 & 96.3 & 96.6 & 96.6 & 96.6 & $<0.001$ \\
\hline Diabetes mellitus & 36.2 & 37.4 & 38.9 & 39.8 & 40.8 & 41.7 & 42.5 & 42.9 & 43.5 & 44.2 & $<0.001$ \\
\hline Previous ischaemic stroke & 37.3 & 39.4 & 41.6 & 42.9 & 44.3 & 45.4 & 46.3 & 47.4 & 47.6 & 48.1 & $<0.001$ \\
\hline Previous MI & 25.7 & 25.7 & 25.4 & 25.1 & 24.3 & 22.8 & 22.0 & 21.6 & 21.0 & 20.9 & $<0.001$ \\
\hline PAD & 12.9 & 14.4 & 16.6 & 19.3 & 21.2 & 22.5 & 23.6 & 24.6 & 25.7 & 26.1 & $<0.001$ \\
\hline Previous major bleeding* & 13.9 & 15.6 & 16.8 & 17.9 & 18.2 & 18.2 & 18.7 & 19.0 & 19.3 & 19.2 & $<0.001$ \\
\hline COPD & 43.7 & 46.3 & 48.1 & 49.2 & 50.0 & 50.4 & 51.3 & 52.0 & 52.6 & 52.6 & $<0.001$ \\
\hline CKD & 10.8 & 11.7 & 12.2 & 13.5 & 13.7 & 14.0 & 15.4 & 16.5 & 16.8 & 18.1 & $<0.001$ \\
\hline $\begin{array}{l}\mathrm{CHA}_{2} \mathrm{DS}_{2} \text {-VASc score, mean } \\
\text { (SE) }\end{array}$ & $\begin{array}{l}4.75 \\
(0.02)\end{array}$ & $\begin{array}{l}4.88 \\
(0.01)\end{array}$ & $\begin{array}{l}5.02 \\
(0.01)\end{array}$ & $\begin{array}{l}5.09 \\
(0.01)\end{array}$ & $\begin{array}{l}5.15 \\
(0.01)\end{array}$ & $\begin{array}{l}5.19 \\
(0.01)\end{array}$ & $\begin{array}{l}5.26 \\
(0.01)\end{array}$ & $\begin{array}{l}5.33 \\
(0.01)\end{array}$ & $\begin{array}{l}5.40 \\
(0.01)\end{array}$ & $\begin{array}{l}5.45 \\
(0.01)\end{array}$ & $<0.001$ \\
\hline HAS-BLED score, mean (SE) & $\begin{array}{l}3.08 \\
(0.01)\end{array}$ & $\begin{array}{l}3.20 \\
(0.01)\end{array}$ & $\begin{array}{l}3.28 \\
(0.01)\end{array}$ & $\begin{array}{l}3.35 \\
(0.01)\end{array}$ & $\begin{array}{l}3.38 \\
(0.01)\end{array}$ & $\begin{array}{l}3.41 \\
(0.01)\end{array}$ & $\begin{array}{l}3.43 \\
(0.01)\end{array}$ & $\begin{array}{l}3.46 \\
(0.01)\end{array}$ & $\begin{array}{l}3.48 \\
(0.01)\end{array}$ & $\begin{array}{l}3.48 \\
(0.01)\end{array}$ & $<0.001$ \\
\hline
\end{tabular}

* Major bleeding includes intracranial bleeding and gastrointestinal bleeding.

$\mathrm{AF}$, atrial fibrillation; CKD, chronic kidney disease; COPD, chronic obstructive pulmonary disease; MI, myocardial infarction; PAD, peripheral artery disease. 
Table 2 Trends of AF hospitalisation per 1 million Korean population between 2006 and 2015

\begin{tabular}{|c|c|c|c|c|c|c|c|c|c|c|c|c|}
\hline & 2006 & 2007 & 2008 & 2009 & 2010 & 2011 & 2012 & 2013 & 2014 & 2015 & $\begin{array}{l}\text { Relative } \\
\text { increase*, } \\
\%\end{array}$ & $\begin{array}{l}\text { P value for } \\
\text { trend }\end{array}$ \\
\hline Overall & 767 & 997 & 1275 & 1529 & 1854 & 2048 & 2497 & 2914 & 3397 & 3986 & 420 & $<0.001$ \\
\hline \multicolumn{13}{|l|}{ Age (years) } \\
\hline 20-49 & 58 & 71 & 85 & 92 & 111 & 117 & 124 & 121 & 131 & 145 & 150 & $<0.001$ \\
\hline $50-59$ & 497 & 572 & 656 & 748 & 855 & 886 & 1013 & 1108 & 1162 & 1303 & 162 & $<0.001$ \\
\hline $60-69$ & 2013 & 2370 & 2689 & 3058 & 3483 & 3666 & 4136 & 4342 & 4449 & 4856 & 141 & $<0.001$ \\
\hline $70-79$ & 5249 & 6777 & 8504 & 9488 & 11120 & 11631 & 13227 & 15148 & 17246 & 19242 & 267 & $<0.001$ \\
\hline$\geq 80$ & 8185 & 10805 & 14459 & 17890 & 21402 & 24034 & 29887 & 35174 & 41429 & 48388 & 491 & $<0.001$ \\
\hline \multicolumn{13}{|l|}{ Sex } \\
\hline Male & 827 & 1039 & 1302 & 1561 & 1853 & 2037 & 2457 & 2817 & 3204 & 3727 & 350 & $<0.001$ \\
\hline Female & 707 & 956 & 1249 & 1497 & 1856 & 2059 & 2535 & 3009 & 3588 & 4242 & 500 & $<0.001$ \\
\hline \multicolumn{13}{|c|}{ Main cause of hospitalisation } \\
\hline Major bleeding $\dagger$ & 241 & 348 & 440 & 516 & 592 & 638 & 735 & 793 & 869 & 966 & 301 & $<0.001$ \\
\hline Ischaemic stroke & 179 & 211 & 247 & 270 & 302 & 326 & 348 & 357 & 369 & 387 & 116 & $<0.001$ \\
\hline AF controlł & 89 & 114 & 134 & 158 & 184 & 214 & 260 & 282 & 318 & 350 & 294 & $<0.001$ \\
\hline $\mathrm{Ml}$ & 142 & 170 & 192 & 207 & 215 & 189 & 204 & 216 & 239 & 274 & 94 & $<0.001$ \\
\hline Heart failure & 297 & 388 & 450 & 502 & 555 & 589 & 619 & 651 & 690 & 732 & 146 & $<0.001$ \\
\hline SSS or PM related & 20 & 24 & 23 & 25 & 27 & 33 & 36 & 44 & 49 & 52 & 20 & $<0.001$ \\
\hline RFCA for AF & 8 & 9 & 8 & 15 & 20 & 25 & 30 & 31 & 34 & 40 & 413 & $<0.001$ \\
\hline
\end{tabular}

*2015 value minus 2006 value divided by 2006 value multiplied by 100 .

tMajor bleeding includes intracranial bleeding and gastrointestinal bleeding.

¥Admission for anticoagulation, rate and rhythm control for AF (AF as principal discharge diagnosis).

AF, atrial fibrillation; MI, myocardial infarction; PM, pacemaker; RFCA, radiofrequency catheter ablation; SSS, sick sinus syndrome.

by identifying NHIS database claims. Medication use among patients with AF in a given year was defined when the medication was prescribed for $>180$ days in the particular year.

\section{Statistical analysis}

AF hospitalisations are presented as numbers per 1 million Korean population and as numbers per 100 patients with AF in a given year. Hospitalisations per 1 million Koreans were the number of hospitalisations in a given year divided by the total number of Korean residents who were alive in that year. Online supplementary table 2 shows the number and distribution of total Korean residents aged $\geq 20$ years. Hospitalisations per 100 patients with AF were the number of hospitalisations in a given year divided by the total number of Korean patients with $\mathrm{AF}$ in that year and multiplied by 100 . The Cochran-Armitage trend test was used to analyse temporal trends of categorical variables. For continuous variables such as hospitalisation costs, the non-parametric test for trends by Jonckheere-Terpstra was used. All tests were two-tailed, with $\mathrm{P}<0.05$ considered to be statistically significant. Statistical analyses were conducted with SAS V.9.4 (SAS Institute, Cary, North Carolina, USA) and SPSS V.23.0 statistical package (SPSS, Chicago, Illinois, USA).

\section{RESULTS}

\section{AF hospitalisations, demographics and comorbidities}

The characteristics of patients with AF who were hospitalised are presented in table 1 . The proportion of patients with AF who were hospitalised in a given year compared with the total Korean patient population with $\mathrm{AF}$ in that year increased from $6.2 \%$ in 2006 to $9.1 \%$ in 2015 . The proportion of females showed a modest increase, changing from $44.6 \%$ in 2006 to $46.4 \%$ in $2015(\mathrm{P}<0.001)$. The mean age increased from 69.5 (SE: 0.9) years in 2006 to 73.3 (SE: 0.5) years in 2015 (P<0.001). The proportion of elderly patients aged $\geq 70$ years increased from $55.5 \%$ in 2006 to $69.5 \%$ in $2015(\mathrm{P}<0.001)$.
The most frequent coexisting conditions in hospitalised patients with AF were hypertension, heart failure and chronic obstructive pulmonary disease. Over the study period, the prevalence of several comorbid diseases increased significantly, with the largest increase of peripheral artery disease (2.0-fold; 12.9\%-26.1\%). Chronic kidney disease (CKD) also increased by 1.7 -fold, from $10.8 \%$ in 2006 to $18.1 \%$ in 2015 . $\mathrm{CHA}_{2} \mathrm{DS}_{2}$ VASc score and HAS-BLED score also significantly increased over the decade. The proportion of patients with intermediate and high economic status also increased significantly, while the proportion of low economic status decreased. The proportion of patients with AF initially diagnosed in primary care hospitals increased significantly, whereas the proportion of those diagnosed in secondary or tertiary referral hospitals decreased.

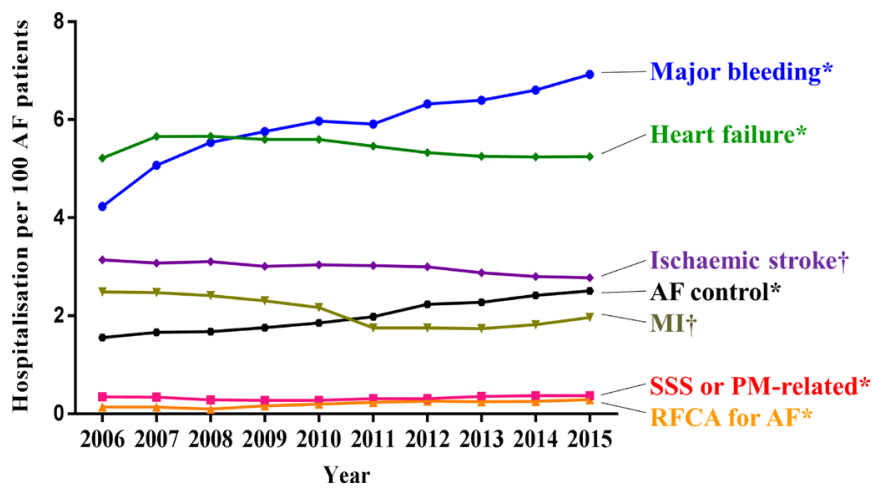

Figure 1 Temporal trends of AF hospitalisation per 100 patients with AF according to main hospitalisation causes between 2006 and 2015. * $P$ value for increase trends $<0.001$. $+P$ value for decrease trends $<0.001$. AF, atrial fibrillation; $\mathrm{MI}$, myocardial infarction; $\mathrm{PM}$, pacemaker; RFCA, radiofrequency catheter ablation; SSS, sick sinus syndrome. 
Table 3 Trends of AF hospitalisation cost between 2006 and 2015

\begin{tabular}{|c|c|c|c|c|c|c|c|c|c|c|c|c|}
\hline & 2006 & 2007 & 2008 & 2009 & 2010 & 2011 & 2012 & 2013 & 2014 & 2015 & $\begin{array}{l}\text { Relative } \\
\text { increase*, } \\
\%\end{array}$ & $\begin{array}{l}\mathrm{P} \text { value for } \\
\text { trend }\end{array}$ \\
\hline Overall & 68.4 & 90.1 & 111.3 & 135.8 & 172.1 & 187.7 & 223.9 & 262.4 & 314.7 & 388.4 & 468 & $<0.001$ \\
\hline \multicolumn{13}{|l|}{ Age (years) } \\
\hline $20-49$ & 3.9 & 4.9 & 5.3 & 5.4 & 7.0 & 7.6 & 7.5 & 8.1 & 9.1 & 11.3 & 187 & $<0.001$ \\
\hline $50-59$ & 6.9 & 8.6 & 9.4 & 12.8 & 15.0 & 16.6 & 19.9 & 23.3 & 25.7 & 31.0 & 349 & $<0.001$ \\
\hline $60-69$ & 19.3 & 23.8 & 27.2 & 31.7 & 38.7 & 40.2 & 45.4 & 48.5 & 54.8 & 67.9 & 251 & $<0.001$ \\
\hline $70-79$ & 26.1 & 36.2 & 46.1 & 54.8 & 69.1 & 75.2 & 88.6 & 104.2 & 124.3 & 145.9 & 460 & $<0.001$ \\
\hline$\geq 80$ & 12.1 & 16.7 & 23.4 & 31.0 & 42.3 & 48.2 & 62.4 & 78.4 & 100.8 & 132.3 & 991 & $<0.001$ \\
\hline \multicolumn{13}{|l|}{ Sex } \\
\hline Male & 39.0 & 50.0 & 60.3 & 73.7 & 90.3 & 97.9 & 116.1 & 133.9 & 158.0 & 194.5 & 399 & $<0.001$ \\
\hline Female & 29.4 & 40.1 & 50.9 & 62.0 & 81.8 & 89.9 & 107.8 & 128.5 & 156.7 & 194.0 & 559 & $<0.001$ \\
\hline \multicolumn{13}{|l|}{ Economic status } \\
\hline Low & 29.0 & 39.4 & 48.5 & 59.8 & 75.5 & 82.8 & 96.1 & 111.3 & 127.5 & 149.4 & 415 & $<0.001$ \\
\hline Intermediate & 14.0 & 18.3 & 27.8 & 30.7 & 38.6 & 42.2 & 49.8 & 59.0 & 69.5 & 87.9 & 531 & $<0.001$ \\
\hline High & 25.4 & 32.4 & 34.9 & 45.3 & 58.0 & 62.7 & 77.9 & 92.1 & 117.7 & 151.1 & 494 & $<0.001$ \\
\hline \multicolumn{13}{|l|}{$\mathrm{CHA}_{2} \mathrm{DS}_{2}-\mathrm{VASC}$} \\
\hline $0-1$ & 2.5 & 3.1 & 3.2 & 3.9 & 4.9 & 5.7 & 6.3 & 6.7 & 6.8 & 8.2 & 223 & $<0.001$ \\
\hline$\geq 2$ & 65.8 & 87.1 & 108.0 & 131.7 & 167.2 & 182.0 & 217.5 & 255.8 & 307.9 & 380.2 & 478 & $<0.001$ \\
\hline \multicolumn{13}{|c|}{ Main cause of hospitalisation } \\
\hline Major bleeding $\dagger$ & 37.1 & 48.8 & 57.8 & 68.7 & 80.5 & 81.3 & 92.1 & 96.9 & 110.4 & 123.6 & 233 & $<0.001$ \\
\hline Ischaemic stroke & 22.8 & 27.6 & 32.9 & 37.1 & 41.9 & 45.5 & 46.9 & 48.4 & 51.4 & 61.1 & 168 & $<0.001$ \\
\hline $\mathrm{AF}$ controlf & 5.9 & 7.6 & 8.0 & 10.5 & 13.3 & 15.9 & 19.5 & 21.1 & 26.9 & 33.2 & 468 & $<0.001$ \\
\hline $\mathrm{Ml}$ & 16.7 & 19.3 & 19.7 & 20.9 & 21.7 & 18.7 & 19.7 & 20.5 & 23.7 & 28.5 & 71 & $<0.001$ \\
\hline Heart failure & 16.1 & 21.9 & 24.9 & 28.4 & 33.1 & 35.4 & 37.8 & 41.5 & 46.1 & 52.1 & 223 & $<0.001$ \\
\hline SSS or PM related & 4.3 & 5.2 & 4.2 & 4.7 & 5.2 & 6.1 & 7.2 & 9.2 & 10.6 & 11.7 & 172 & $<0.001$ \\
\hline RFCA for AF & 2.2 & 2.7 & 2.1 & 4.0 & 5.4 & 7.2 & 8.9 & 9.0 & 12.0 & 16.4 & 660 & $<0.001$ \\
\hline
\end{tabular}

All costs are adjusted for inflation by calculating in terms of 2015 cost according to Korean Consumer Price Index data and presented as million $€$.

*2015 value minus 2006 value divided by 2006 value multiplied by 100 .

tMajor bleeding includes intracranial bleeding and gastrointestinal bleeding.

$\ddagger$ Admission for anticoagulation, rate and rhythm control for AF (AF as principal discharge diagnosis).

AF, atrial fibrillation; MI, myocardial infarction; PM, pacemaker; RFCA, radiofrequency catheter ablation; SSS, sick sinus syndrome.

\section{Trends of AF hospitalisations}

From 2006 to 2015, the overall hospitalisation rate per 1 million Korean population increased significantly from 767 to 3986 per 1 million Koreans (relative increase, 420\%; $\mathrm{P}<0.001$; table 2). The significant increase of hospitalisation rate was observed across all age groups. The largest increase in hospitalisation rate was observed in the group aged $\geq 80$ years (491\%), followed by the group aged 70-79 years (267\%). The relative rates of increase were higher in females than males $(500 \%$ vs $350 \%$; $<<0.001)$. Therefore, the hospitalisation rate was higher in men from 2006 to 2009 , but was higher in women since 2010. Hospitalisation due to major bleeding increased by $301 \%$, from 241 to 966 per 1 million Koreans from 2006 to 2015 ( $\mathrm{P}<0.001)$. Hospitalisation due to ischaemic stroke, AF control, MI and heart failure also increased by $116 \%, 294 \%, 94 \%$ and 146\%, respectively (all $\mathrm{P}<0.001)$.

The overall hospitalisation rate per 100 patients with AF also increased significantly from 13.4 in 2006 to 28.6 in 2015 (relative increase $113 \% ; \mathrm{P}<0.001$ ). The increasing trend was consistent across all subgroups according to economic status and $\mathrm{CHA}_{2} \mathrm{DS}_{2}$-VASc score (all $\mathrm{P}<0.001$, online supplementary table 3). Mean hospitalisations per 100 patients with AF with high $\mathrm{CHA}_{2} \mathrm{DS}_{2}$-VASc score $(\geq 2)$ were consistently higher than those with $\mathrm{CHA}_{2} \mathrm{DS}_{2}$-VASc score from 0 to 1 . Figure 1 shows the temporal trends of AF hospitalisations per 100 patients with AF according to main hospitalisation cause. The hospitalisations per 100 patients with AF mainly due to major bleeding,
AF control, heart failure and SSS or PM related increased by $64 \%, 61 \%, 1 \%$ and $8 \%$, respectively (all $\mathrm{P}<0.001$ ). The magnitude of the increase in hospitalisation rates per 100 patients with AF was highest with RFCA for AF (110\%; P<0.001). However, hospitalisations mainly due to ischaemic stroke $(-12 \% ; \mathrm{P}<0.001)$ and $\mathrm{MI}(-21 \% ; \mathrm{P}<0.001)$ per 100 patients with AF decreased.

\section{Trends of AF hospitalisation costs}

Table 3 shows temporal trends of AF hospitalisation costs. After adjusting for inflation, the overall cost of AF hospitalisations increased exponentially from €68.4 million in 2006 to $€ 388.4$ million in 2015 (relative increase, 468\%; $\mathrm{P}<0.001$ ). Across all subgroups according to age, sex, economic status and $\mathrm{CHA}_{2} \mathrm{DS}_{2}$-VASc score, the inpatient costs increased significantly (all $\mathrm{P}<0.001$ ).

The total inpatient costs mainly due to major bleeding increased from €37.1 million in 2006 to $€ 123.6$ million in 2015 (relative increase, 233\%; $\mathrm{P}<0.001$ ). Total inpatient costs mainly due to ischaemic stroke, AF control and MI also increased by 168\%, 468\% and 71\%, respectively (all $\mathrm{P}<0.001$ ).

Over the same period, the annual Korean NHIS total expenditure increased by $58 \%$ from $€ 31589$ million to $€ 49898$ million. ${ }^{19}$ The proportion of AF hospitalisation cost to Korean NHIS total expenditure increased from $0.22 \%$ in 2006 to $0.78 \%$ in 2015 (figure 2, online supplementary table 4). 
A

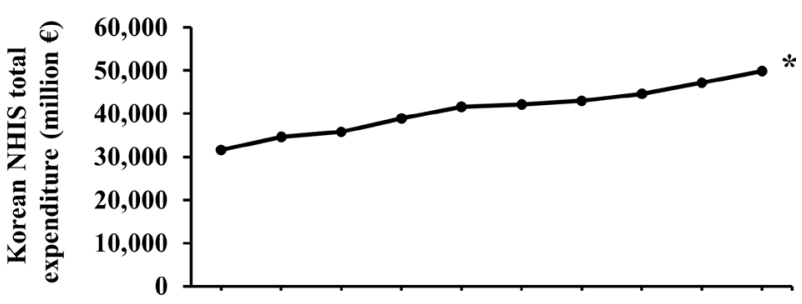

B

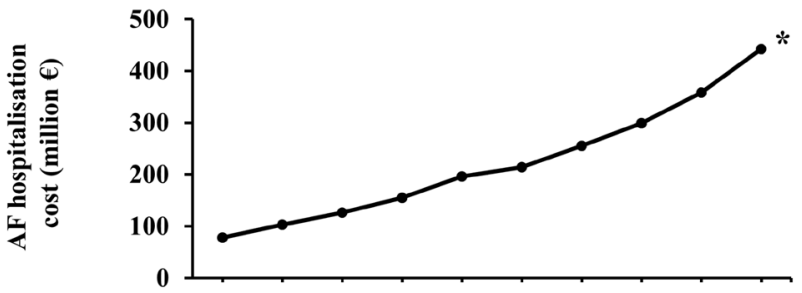

C

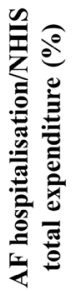

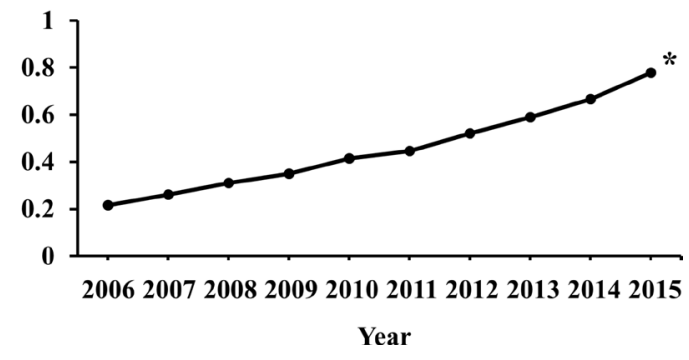

Figure 2 Temporal trends of medical cost between 2006 and 2015.

(A) Korean NHIS total expenditure (million $€$ ), (B) total AF hospitalisation cost (million $€$ ) and (C) the proportion of total AF hospitalisation cost to Korean NHIS total expenditure (\%). ${ }^{*} \mathrm{P}$ value for trends $<0.001$. AF, atrial fibrillation; NHIS, National Health Insurance Service.

Mean cost per hospitalisation for overall AF hospitalisation decreased by $3 \%$ from $€ 2407$ to $€ 2337(\mathrm{P}<0.001)$. Mean cost per hospitalisation mainly due to ischaemic stroke, AF control, heart failure and RFCA for AF increased over the decade; however, mean cost per hospitalisation due to major bleeding and MI decreased over this period (table 4).

\section{Trends of AF treatment patterns}

Table 5 shows the trends in AF treatment patterns. The use of oral anticoagulants significantly increased by 36\% (from $26.8 \%$ to $36.4 \%$; $\mathrm{P}<0.001$ ), with increasing trends in both warfarin and non-vitamin K-dependent oral anticoagulant use. The use of $\mathrm{P}_{2} \mathrm{Y}_{12}$ inhibitors and statins increased by $165 \%$ and $160 \%$, respectively, whereas aspirin use decreased by $19 \%$ (all $\mathrm{P}<0.001)$. Usage of digoxin decreased by $49 \%$, while that of class Ic anti-arrhythmic drugs increased by $80 \%$ (both $\mathrm{P}<0.001$ ).

\section{In-hospital mortality and length of stay}

Table 6 shows the trends of in-hospital mortality following AF hospitalisation. Overall in-hospital mortality significantly decreased from $7.5 \%$ in 2006 to $4.3 \%$ in 2015 (relative decrease $42 \%, \mathrm{P}<0.001)$. The in-hospital mortality was highest in patients aged $\geq 80$ years $(7.7 \%)$ and in those with CKD (7.4\%) and major bleeding (7.3\%).

While mean lengths of hospital stay mainly due to major bleeding, ischaemic stroke, AF control, SSS or PM related and RFCA for AF decreased, those due to heart failure and MI increased over the time period from 2006 to 2015 (see online supplementary table 5 ).

\section{DISCUSSION}

The main findings of our analysis of AF hospitalisation over a 10-year period in Korea are as follows: (1) AF hospitalisations have increased significantly for the last decade; (2) the majority of admissions occurred in elderly patients aged $\geq 70$ years, and those aged $\geq 80$ years demonstrated the largest increase of admissions and the greatest in-hospital mortality among all age groups; (3) the total costs of AF care were increased even after adjusting for inflation, with the proportion of AF hospitalisation costs to Korean NHIS total expenditure increasing to $0.78 \%$ in 2015 and (4) mortality associated with AF hospitalisations decreased significantly.

\section{Increased AF hospitalisation}

Our finding of increased AF hospitalisation rates is consistent with other nationwide studies. ${ }^{20} 21$ The increase of AF hospitalisation might be attributable to ageing of the general population and the increasing prevalence of risk factors including hypertension, diabetes mellitus and obesity. ${ }^{12}{ }^{17}$ Almost $80 \%$ of hospitalised patients were $\geq 70$ years of age, consistent with previous studies. ${ }^{31}$ Patients aged $\geq 80$ years had the largest hospitalisation rate for any age group throughout the 10-year period, and had an exponential increase from 8185 in 2006 to 48388 per 1 million people per year in 2015. Moreover, the in-hospital

Table 4 Mean cost per hospitalisation

\begin{tabular}{|c|c|c|c|c|c|c|c|c|c|c|c|c|}
\hline & 2006 & 2007 & 2008 & 2009 & 2010 & 2011 & 2012 & 2013 & 2014 & 2015 & $\begin{array}{l}\text { increase*, } \\
\%\end{array}$ & $\begin{array}{l}\text { P value for } \\
\text { trend }\end{array}$ \\
\hline Overall AF hospitalisation, $€$ & 2407 & 2404 & 2290 & 2304 & 2380 & 2318 & 2238 & 2218 & 2250 & 2337 & -3 & $<0.001$ \\
\hline \multicolumn{13}{|l|}{ Main cause of hospitalisation, $€$} \\
\hline Major bleedingt & 4155 & 3725 & 3448 & 3456 & 3481 & 3224 & 3133 & 3009 & 3085 & 3067 & -26 & $<0.001$ \\
\hline Ischaemic stroke & 3431 & 3486 & 3501 & 3566 & 3556 & 3525 & 3364 & 3342 & 3389 & 3780 & 10 & $<0.001$ \\
\hline AF controlł & 1776 & 1783 & 1562 & 1728 & 1840 & 1878 & 1875 & 1848 & 2047 & 2271 & 28 & $<0.001$ \\
\hline $\mathrm{Ml}$ & 3175 & 3020 & 2685 & 2617 & 2581 & 2504 & 2416 & 2343 & 2403 & 2492 & -22 & $<0.001$ \\
\hline Heart failure & 1465 & 1505 & 1451 & 1469 & 1527 & 1515 & 1524 & 1569 & 1623 & 1707 & 16 & $<0.001$ \\
\hline SSS or PM related & 5887 & 5887 & 4872 & 4854 & 4816 & 4570 & 4992 & 5119 & 5255 & 5391 & -8 & $<0.001$ \\
\hline RFCA for AF & 7407 & 7554 & 6895 & 7111 & 7023 & 7204 & 7249 & 7176 & 8601 & 9742 & 32 & $<0.001$ \\
\hline
\end{tabular}

All costs are adjusted for inflation by calculating in terms of 2015 cost according to Korean Consumer Price Index data and presented as $€$.

*2015 value minus 2006 value divided by 2006 value multiplied by 100 .

tMajor bleeding includes intracranial bleeding and gastrointestinal bleeding.

¥Admission for anticoagulation, rate and rhythm control for AF (AF as principal discharge diagnosis).

AF, atrial fibrillation; MI, myocardial infarction; PM, pacemaker; RFCA, radiofrequency catheter ablation; SSS, sick sinus syndrome. 
Table 5 Trends of AF treatment patterns between 2006 and 2015

\begin{tabular}{|c|c|c|c|c|c|c|c|c|c|c|c|c|}
\hline & 2006 & 2007 & 2008 & 2009 & 2010 & 2011 & 2012 & 2013 & 2014 & 2015 & $\begin{array}{l}\text { Relative } \\
\text { increase*, } \\
\%\end{array}$ & $\begin{array}{l}P \text { value for } \\
\text { trend }\end{array}$ \\
\hline OAC & 26.8 & 27.5 & 27.2 & 27.8 & 28.0 & 29.5 & 30.3 & 32.0 & 33.5 & 36.4 & 36 & $<0.001$ \\
\hline NOAC & 0.0 & 0.0 & 0.0 & 0.0 & 0.0 & 0.0 & 0.0 & 1.9 & 2.5 & 9.8 & & $<0.001$ \\
\hline Aspirin & 46.2 & 47.0 & 47.1 & 47.6 & 47.1 & 45.9 & 45.5 & 44.2 & 41.7 & 37.4 & -19 & $<0.001$ \\
\hline $\mathrm{P} \mathrm{Y}_{12}$ inhibitor & 5.9 & 7.6 & 9.4 & 11.2 & 11.1 & 11.0 & 11.9 & 13.4 & 15.2 & 15.7 & 165 & $<0.001$ \\
\hline$\beta$-Blocker & 44.7 & 46.0 & 46.6 & 47.9 & 47.7 & 47.8 & 45.8 & 44.2 & 42.1 & 40.1 & -10 & $<0.001$ \\
\hline Calcium channel blocker & 20.8 & 21.3 & 21.8 & 22.5 & 22.5 & 22.4 & 21.9 & 21.5 & 21.1 & 20.6 & -1 & $<0.001$ \\
\hline Digoxin & 32.7 & 30.5 & 28.3 & 26.7 & 24.8 & 23.6 & 21.8 & 20.2 & 18.5 & 16.7 & -49 & $<0.001$ \\
\hline AAD class Ic & 6.0 & 6.4 & 6.7 & 7.2 & 7.7 & 8.9 & 9.6 & 10.0 & 10.4 & 10.8 & 80 & $<0.001$ \\
\hline AAD class III & 5.9 & 5.9 & 5.8 & 5.5 & 5.4 & 5.4 & 5.4 & 5.5 & 5.8 & 6.0 & 1 & 0.287 \\
\hline
\end{tabular}

Values are percentages of each drug user type among patients with AF hospitalisations.

*2015 value minus 2006 value divided by 2006 value multiplied by 100 .

$A A D$, anti-arrhythmic drug; $A F$, atrial fibrillation; NOAC, non-vitamin K-dependent oral anticoagulant; OAC, oral anticoagulant.

mortality in this age group was highest among all age groups. It is expected that the number of elderly Koreans aged $\geq 75$ years will increase from 2.05 million in 2010 to 5.08 million in 2030, and to 11.0 million in $2060 .{ }^{22}$ Increasing AF hospitalisations with high mortality in this elderly group will give rise to an increased public healthcare burden and associated healthcare costs.

Since 2010, women had higher AF hospitalisation rates than men, with a higher rate of increase during 10 years. This sex

Table 6 In-hospital mortality for AF hospitalisation

\begin{tabular}{|c|c|c|c|c|c|c|c|c|c|c|c|c|c|}
\hline & 2006 & 2007 & 2008 & 2009 & 2010 & 2011 & 2012 & 2013 & 2014 & 2015 & Overall & $\begin{array}{l}\text { Relative } \\
\text { increase*, } \\
\%\end{array}$ & $\begin{array}{l}P \text { value for } \\
\text { trend }\end{array}$ \\
\hline Overall, \% & 7.5 & 7.4 & 7.3 & 6.6 & 6.6 & 6.1 & 6.0 & 5.5 & 4.8 & 4.3 & 5.7 & -42 & $<0.001$ \\
\hline \multicolumn{14}{|l|}{ Age (years), \% } \\
\hline $20-49$ & 3.1 & 3.3 & 3.1 & 2.3 & 2.2 & 1.8 & 1.8 & 1.9 & 1.5 & 1.7 & 2.1 & -45 & $<0.001$ \\
\hline $50-59$ & 4.6 & 4.4 & 4.1 & 3.5 & 2.9 & 2.8 & 2.9 & 2.2 & 2.0 & 1.9 & 2.8 & -59 & $<0.001$ \\
\hline $60-69$ & 5.7 & 5.6 & 5.5 & 5.1 & 4.8 & 4.2 & 3.9 & 3.7 & 3.2 & 2.7 & 4.1 & -53 & $<0.001$ \\
\hline $70-79$ & 8.0 & 7.9 & 7.3 & 6.6 & 6.6 & 6.1 & 5.9 & 5.5 & 4.6 & 4.1 & 5.7 & -49 & $<0.001$ \\
\hline$\geq 80$ & 11.3 & 10.7 & 11.0 & 9.6 & 9.5 & 8.8 & 8.5 & 7.4 & 6.4 & 5.7 & 7.7 & -50 & $<0.001$ \\
\hline \multicolumn{14}{|l|}{ Sex, \% } \\
\hline Male & 7.7 & 7.7 & 7.6 & 6.8 & 6.9 & 6.4 & 6.3 & 5.9 & 5.4 & 4.8 & 6.1 & -38 & $<0.001$ \\
\hline Female & 7.3 & 7.1 & 7.1 & 6.4 & 6.3 & 5.9 & 5.8 & 5.2 & 4.3 & 3.9 & 5.3 & -46 & $<0.001$ \\
\hline \multicolumn{14}{|l|}{ Economic status, \% } \\
\hline Low & 6.5 & 6.6 & 6.7 & 6.2 & 6.3 & 6.0 & 6.0 & 5.4 & 4.6 & 4.2 & 5.5 & -35 & $<0.001$ \\
\hline Intermediate & 7.2 & 7.9 & 7.8 & 7.1 & 6.9 & 6.0 & 5.7 & 5.7 & 5.0 & 4.2 & 5.8 & -41 & $<0.001$ \\
\hline High & 8.9 & 8.2 & 8.1 & 7.0 & 6.9 & 6.5 & 6.3 & 5.7 & 4.9 & 4.5 & 5.9 & -50 & $<0.001$ \\
\hline \multicolumn{14}{|l|}{$\mathrm{CHA}_{2} \mathrm{DS}_{2}-\mathrm{VASC}, \%$} \\
\hline $0-1$ & 4.3 & 4.2 & 3.6 & 3.2 & 3.2 & 2.6 & 2.4 & 2.2 & 1.8 & 1.8 & 2.7 & -58 & $<0.001$ \\
\hline$\geq 2$ & 7.6 & 7.5 & 7.5 & 6.7 & 6.7 & 6.2 & 6.1 & 5.6 & 4.9 & 4.4 & 5.8 & -43 & $<0.001$ \\
\hline \multicolumn{14}{|l|}{ Comorbidities, \% } \\
\hline Heart failure & 7.5 & 7.7 & 7.7 & 7.0 & 7.0 & 6.6 & 6.4 & 5.9 & 5.1 & 4.6 & 6.0 & -40 & $<0.001$ \\
\hline Hypertension & 7.3 & 7.3 & 7.2 & 6.6 & 6.5 & 6.1 & 6.0 & 5.5 & 4.8 & 4.3 & 5.7 & -41 & $<0.001$ \\
\hline Diabetes mellitus & 10.0 & 9.2 & 9.5 & 8.3 & 8.2 & 7.7 & 7.4 & 6.8 & 5.7 & 5.2 & 7.0 & -49 & $<0.001$ \\
\hline Previous ischaemic stroke & 8.3 & 8.0 & 7.6 & 7.0 & 6.6 & 6.1 & 6.0 & 5.5 & 4.6 & 4.1 & 5.6 & -50 & $<0.001$ \\
\hline Previous MI & 9.6 & 8.8 & 8.7 & 8.0 & 7.7 & 7.6 & 7.0 & 6.6 & 5.6 & 5.1 & 6.9 & -47 & $<0.001$ \\
\hline PAD & 8.1 & 7.6 & 7.3 & 6.5 & 6.9 & 6.4 & 6.5 & 6.0 & 5.2 & 4.7 & 5.9 & -41 & $<0.001$ \\
\hline Previous major bleeding $†$ & 11.4 & 10.1 & 9.8 & 9.0 & 8.4 & 7.9 & 7.9 & 7.1 & 5.9 & 5.1 & 7.3 & -55 & $<0.001$ \\
\hline COPD & 7.6 & 7.9 & 8.1 & 7.3 & 7.3 & 6.9 & 6.8 & 6.3 & 5.4 & 5.0 & 6.3 & -35 & $<0.001$ \\
\hline CKD & 10.8 & 10.1 & 9.8 & 9.4 & 9.1 & 8.3 & 8.0 & 7.1 & 6.5 & 5.5 & 7.4 & -49 & $<0.001$ \\
\hline
\end{tabular}

*2015 value minus 2006 value divided by 2006 value multiplied by 100 .

†Major bleeding includes intracranial bleeding and gastrointestinal bleeding.

$A F$, atrial fibrillation; $C K D$, chronic kidney disease; COPD, chronic obstructive pulmonary disease; MI, myocardial infarction; PAD, peripheral artery disease. 
difference is similar to that reported in previous studies in the USA and Scotland, ${ }^{21} 23$ and might be explained by a higher symptom burden and stroke risk in women with $\mathrm{AF}^{24}$

\section{Hospitalisation costs}

In this study, total hospital costs per year increased exponentially by $468 \%$ over a 10-year follow-up. The annual Korean NHIS total expenditure increased by only $58 \%$, while the proportion of AF hospitalisation cost to Korean NHIS total expenditure increased to $0.78 \%$ in 2015 . Consistent with our findings, many previous studies have shown that the number of AF-related hospital costs have increased with ageing of the population and more prevalent risk factors such as hypertension and diabetes. ${ }^{2021}$ Moreover, the number of RFCA shows a consistent increase over the past decade, which could contribute to the rise of hospital costs.

The mean length of hospital stays due to various causes, except heart failure and MI, decreased from 2006 to 2015 and mean cost per hospitalisation showed a slight decrease of $-3 \%$ for the same period (perhaps related to the strong regulation of medication price and medical practice by the strict reimbursement system of Korea); however, the total cost increased significantly over the 10-year period. Increasing number of hospitalisations, ageing and increasing patients' comorbidities and complexities are some drivers of these increasing costs, causing a major economic problem on the healthcare system.

Compared with some other countries, ${ }^{21}$ the mean length of hospital stay in Korea was significantly longer. This might be related to cheaper hospitalisation costs and generous reimbursement policies in Korea. Therefore, we should focus on limiting hospitalisations and on shortening the lengths of hospital stay. There are some potential means to reduce the cost of AF care, such as emergency department observation unit for acute onset $\mathrm{AF}$, rhythm versus rate control and low molecular weight heparin use in patients hospitalised for $\mathrm{AF}^{25-27}$

\section{Treatment pattern and in-hospital mortality}

Previous studies have reported that global burden of AF has increased exponentially. ${ }^{21}{ }^{28}$ However, patients with AF showed a modest decrease in in-hospital mortality over the 10-year study period in our study. The rising prevalence and longer survival after onset of $\mathrm{AF}$ might be attributable, in part, to early disease detection due to improvements in surveillance methods and general medical care.

Along with decreased in-hospital mortality, we showed declines over time in stroke and MI admissions occurring in patients with AF. Our findings are in line with data that show a decline in stroke rates, including thromboembolic strokes, during the past few decades. ${ }^{29}$ In contrast, the number of hospitalisations mainly due to major bleeding among patients with AF increased over a 10 -year period. These dual findings of decreasing stroke and $\mathrm{MI}$ and increasing bleeding admissions seemed to coincide with increased use of oral anticoagulants and $\mathrm{P}_{2} \mathrm{Y}_{12}$ inhibitors along with decreased use of aspirin. The switching of antithrombotic therapy from aspirin to oral anticoagulant as well as the increased use of $\mathrm{P} 2 \mathrm{Y}_{12}$ inhibitors might help explain the decreased stroke and $\mathrm{MI}$ admissions and increased bleeding admissions.

\section{Limitations}

The present study has several limitations. Such studies using administrative databases might be susceptible to errors from coding inaccuracies. To minimise this problem, we examined the nationwide cohort and applied the definition that we already validated in previous studies that used a Korean NHIS sample cohort. ${ }^{13-17}$ Since we defined AF cases only with ICD-10 codes, it is possible that either paroxysmal or asymptomatic AF cases, which were not ascertained by these codes, were not recorded. Also, we could not analyse paroxysmal, persistent and permanent AF subgroups separately. We could not distinguish index admissions from re-admissions in the NHIS database, potentially leading to an overestimation of the number of hospitalisations. This study examines only in-hospital mortality without follow-up outcomes. However, this study analysed longitudinal data from the entire adult Korean population, using the largest nationwide Asian database available in the literature. Therefore, our findings should reflect the 'real-world' AF burden on a nationwide scale.

\section{CONCLUSIONS}

Hospitalisation rates for AF among Korean adults increased exponentially from 2006 to 2015, in association with an increase in comorbid chronic diseases. Mortality associated with AF hospitalisations decreased during the last decade, but hospitalisation costs have markedly increased. Prevention of AF hospitalisations and streamlined integrated AF management should be pursued in a holistic manner to lessen the healthcare burden of $\mathrm{AF}^{30}$

\section{Key questions}

\section{What is already known on this subject?}

- The healthcare burden of atrial fibrillation (AF) is growing considerably, and is mainly related to hospitalisations. However, the impact of AF on hospitalisations and mortality, and the economic burden of $A F$ is less understood in Asian populations.

\section{What might this study add?}

- AF hospitalisations have increased exponentially among Korean adults from 2006 to 2015, in association with an increase in comorbid chronic diseases. Mortality associated with AF hospitalisations decreased during the last decade, but hospitalisation costs have markedly increased.

How might this impact on clinical practice?

- Prevention of AF hospitalisations and streamlined integrated AF management should be pursued in a holistic manner to lessen the healthcare burden of AF.

Contributors BJ and GYHL contributed to the conception and design of the work and critical revision of the manuscript. DK contributed to the conception and design of the work, interpretation of data for the work and drafting of the manuscript. P-SY and EJ contributed to the acquisition and analysis of data for the work. HTY, T-HK, J-SU, JYK, H-NP and M-HL contributed to the conception and design of the work and revising the manuscript. All authors approved the final version to be published and agree to be accountable for all aspects of the work in ensuring that questions related to the accuracy or integrity of any part of the work are appropriately investigated and resolved.

Funding This study was supported by a research grant from the Basic Science Research Program through the National Research Foundation of Korea funded by the Ministry of Education, Science and Technology (NRF-2017R1A2B3003303), and grants from the Korean Healthcare Technology R\&D project funded by the Ministry of Health \& Welfare (HI16C0058, HI15C1200)

Competing interests GYHL: consultant for Bayer/Janssen, BMS/Pfizer, Biotronik Medtronic, Boehringer Ingelheim, Novartis, Verseon and Daiichi-Sankyo. Speaker for Bayer, BMS/Pfizer, Medtronic, Boehringer Ingelheim and Daiichi-Sankyo. No fees are directly received personally.

Patient consent Not required.

Ethics approval This study was approved by the Institutional Review Board of Yonsei University Health System (4-2016-0179). 
Provenance and peer review Not commissioned; externally peer reviewed.

(C) Article author(s) (or their employer(s) unless otherwise stated in the text of the article) 2018. All rights reserved. No commercial use is permitted unless otherwise expressly granted.

\section{REFERENCES}

1 Stewart S, Hart CL, Hole DJ, et al. A population-based study of the long-term risks associated with atrial fibrillation: 20-year follow-up of the Renfrew/Paisley study. Am J Med 2002;113:359-64.

2 Miyasaka Y, Barnes ME, Gersh BJ, et al. Secular trends in incidence of atrial fibrillation in Olmsted County, Minnesota, 1980 to 2000, and implications on the projections for future prevalence. Circulation 2006;114:119-25.

3 Krijthe BP, Kunst A, Benjamin EJ, et al. Projections on the number of individuals with atrial fibrillation in the European Union, from 2000 to 2060. Eur Heart J 2013:34:2746-51.

4 Go AS, Hylek EM, Phillips KA, et al. Prevalence of diagnosed atrial fibrillation in adults: national implications for rhythm management and stroke prevention: the AnTicoagulation and Risk Factors in Atrial Fibrillation (ATRIA) Study. JAMA 2001;285:2370-5.

5 Coyne KS, Paramore C, Grandy S, et al. Assessing the direct costs of treating nonvalvular atrial fibrillation in the United States. Value Health 2006;9:348-56.

$6 \mathrm{Kim} \mathrm{MH}$, Johnston SS, Chu BC, et al. Estimation of total incremental health care costs in patients with atrial fibrillation in the United States. Circ Cardiovasc Qual Outcomes 2011:4:313-20.

7 Stewart S, Murphy NF, Murphy N, Walker A, et al. Cost of an emerging epidemic: an economic analysis of atrial fibrillation in the UK. Heart 2004;90:286-92.

8 Lip GYH, Brechin CM, Lane DA. The global burden of atrial fibrillation and stroke: a systematic review of the epidemiology of atrial fibrillation in regions outside North America and Europe. Chest 2012;142:1489-98.

9 Guo Y, Tian Y, Wang H, et al. Prevalence, incidence, and lifetime risk of atrial fibrillation in China: new insights into the global burden of atrial fibrillation. Chest 2015;147:109-19.

10 Tse HF, Wang YJ, Ahmed Ai-Abdullah M, et al. Stroke prevention in atrial fibrillation-an Asian stroke perspective. Heart Rhythm 2013;10:1082-8.

11 Song SO, Jung CH, Song YD, et al. Background and data configuration process of a nationwide population-based study using the korean national health insurance system. Diabetes Metab J 2014;38:395-403.

12 .Baek YS, Yang PS, Kim TH, et al. Associations of Abdominal Obesity and New-Onset Atrial Fibrillation in the General Population. J Am Heart Assoc 2017;6:e004705.

13 Kim TH, Yang PS, Uhm JS, et al. CHA DS, -VASc Score (Congestive Heart Failure, Hypertension, Age $\geq 75$ [Doubled], Diabetes Mellitus, Prior Stroke or Transient Ischemic Attack [Doubled], Vascular Disease, Age 65-74, Female) for Stroke in Asian Patients With Atrial Fibrillation: A Korean Nationwide Sample Cohort Study. Stroke 2017:48:1524-30.
14 Chao TF, Liu CJ, Tuan TC, et al. Rate-control treatment and mortality in atrial fibrillation. Circulation 2015;132:1604-12.

15 Kim TH, Yang PS, Kim D, et al. CHA,DS,-VASc Score for Identifying Truly Low-Risk Atrial Fibrillation for Stroke: A Korean Nationwide Cohort Study. Stroke 2017;48.

16 Lee HY, Yang PS, Kim TH, et al. Atrial fibrillation and the risk of myocardial infarction: a nation-wide propensity-matched study. Sci Rep 2017;7:12716.

17 Lee SS, Ae Kong K, Kim D, et al. Clinical implication of an impaired fasting glucose and prehypertension related to new onset atrial fibrillation in a healthy Asian population without underlying disease: a nationwide cohort study in Korea. Eur Heart J 2017.

18 Statistics Korea. Korean Consumer Price Index. 2015 http://www.kostat.go.kr/portal/ eng/pressReleases/9/2/index.board (accessed 14 Dec 2017).

19 The Korean Health Insurance Review and Assessment Service. Treatment Cost Index. 2015 http://www.hira.or.kr/dummy.do?pgmid=HIRAA020045030000\&cmsurl=/cms/ medi info/07/03/03/1344900 27404.html\&subject=2015\%EB\%85\%84\%20\%EC\% A7\%84\%EB\%A3\%8C\%EB\%B9\%84\%ED\%86\%B5\%EA\%B3\%84\%EC\%A7\%80\% ED\%91\%9C (accessed 28 Nov 2017).

20 Wong CX, Brooks AG, Leong DP, et al. The increasing burden of atrial fibrillation compared with heart failure and myocardial infarction: a 15-year study of all hospitalizations in Australia. Arch Intern Med 2012;172:739-41.

21 Patel NJ, Deshmukh A, Pant S, et al. Contemporary trends of hospitalization for atrial fibrillation in the United States, 2000 through 2010: implications for healthcare planning. Circulation 2014;129:2371-9.

22 Statistics Korea. Population Projections for Korea. 2015 http://www.kostat.go.kr/ portal/eng/pressReleases/8/8/index.board (accessed 28 Nov 2017).

23 Stewart S, Maclntyre K, MacLeod MM, et al. Trends in hospital activity, morbidity and case fatality related to atrial fibrillation in Scotland, 1986-1996. Eur Heart J 2001;22:693-701.

24 Lip GY, Laroche C, Boriani G, et al. Sex-related differences in presentation, treatment, and outcome of patients with atrial fibrillation in Europe: a report from the Euro Observational Research Programme Pilot survey on Atrial Fibrillation. Europace 2015:17:24-31.

25 Decker WW, Smars PA, Vaidyanathan L, et al. A prospective, randomized trial of an emergency department observation unit for acute onset atrial fibrillation. Ann Emerg Med 2008:52:322-8.

26 Kim MH, Decena BF, Bruckman D, et al. Use patterns of low-molecular weight heparin and the impact on length of stay in patients hospitalized for atrial fibrillation. Am Heart J 2003;145:665-9.

27 Marshall DA, Levy AR, Vidaillet $H$, et al. Cost-effectiveness of rhythm versus rate control in atrial fibrillation. Ann Intern Med 2004;141:653-61.

28 Chugh SS, Havmoeller R, Narayanan K, et al. Worldwide epidemiology of atrial fibrillation: a Global Burden of Disease 2010 Study. Circulation 2014;129:837-47.

29 Koton S, Schneider AL, Rosamond WD, et al. Stroke incidence and mortality trends in US communities, 1987 to 2011. JAMA 2014;312:259-68.

30 Lip GYH. The ABC pathway: an integrated approach to improve AF management. Nat Rev Cardiol 2017:14:627-8. 